\title{
ATMOSPHERIC MERCURY IN CHINA STUDIED WITH DIFFERENTIAL ABSORPTION LIDAR
}

\author{
Guangyu Zhao', Zheng Duan ${ }^{1}$, Ming Lian ${ }^{1}$, and Sune Svanberg ${ }^{1,2 *}$ \\ ${ }^{1}$ Center for Optical and Electromagnetic Research, South China Academy of Advanced Optoelectronics, \\ South China Normal University, University City Campus, Guangzhou 510006, China \\ ${ }^{2}$ Department of Physics, Lund University, SE 22100 Lund, Sweden \\ *Email:sune.svanberg@fysik.lth.se
}

\begin{abstract}
Mercury is a very serious environmental pollutant which is intensely studied by many researchers. China is a main producer and consumer of mercury. We have pursued extensive monitoring of atomic mercury using the differential absorption lidar (DIAL) technique, based on a newly constructed mobile monitoring system. Mercury levels in major cities (Guangzhou, Zhengzhou, Xi'an) were measured, as well as in mercury mining areas in Wanshan, Guizhou province. Further, mercury emissions from the Emperor Qin Mausoleum in $\mathrm{Xi}^{\prime}$ an were investigated together with archaeologists.
\end{abstract}

\section{INTRODUCTION}

Mercury is a very serious heavy metal pollutant, which is presently subject to strict international regulations [1]. All aspects of mercury in the environment are studied by a quite large community of researchers. China is a major producer and consumer of mercury [2]. Emissions of mercury are due to coal burning, metal processing, mining activities etc. An important aspect of mercury management is to characterize sources and quantify emissions. Mercury is also an interesting geophysical tracer gas, a fact which is related to its very high vapor pressure even at normal ambient temperatures [3]. Atmospheric mercury is predominantly in elemental, atomic form, making the differential absorption lidar (DIAL) method very sensitive and suitable for mercury mapping. The sensitivity is approaching the level of the Atlantic background, which is of the order on $2 \mathrm{ng} / \mathrm{m}^{3}$. Mercury DIAL monitoring was pioneered by the Lund University lidar group in Sweden, and is now also available in China after the development of a mobile measurement system by the South China Normal University (SCNU) lidar group [4].

\section{METHODOLOGY}

The SCNU mobile laser spectroscopy laboratory, incorporating DIAL capability, is shown in Fig. 1, on site in the Wanshan mining area in the Guizhou province, China. The system incorporates a $20 \mathrm{~Hz}$ high-energy pulsed Nd:YAG laser, the $532 \mathrm{~nm}$ and $355 \mathrm{~nm}$ harmonics of which are used for pumping a narrow-band Sirah dye laser, which for the case of the atomic mercury resonance line close to $254 \mathrm{~nm}$ is operating with the dye Coumarine 307 at $508 \mathrm{~nm}$, followed by frequency doubling. A vertically-looking $40 \mathrm{~cm}$ diameter Newtonian telescope is used in combination with a large roof-top folding mirror for the collection of back-scattered radiation. Recordings for two close-lying on- and offresonance wavelengths with switching between every laser shot, is used for evaluation of the range-resolved mercury concentration profile, as illustrated in Fig. 2. Concentration profiles are evaluated from the DIAL curve, formed as the ratio between the on- and off-resonance recordings, as described in [5] and illustrated in the figure. We note, that a high slope on the DIAL

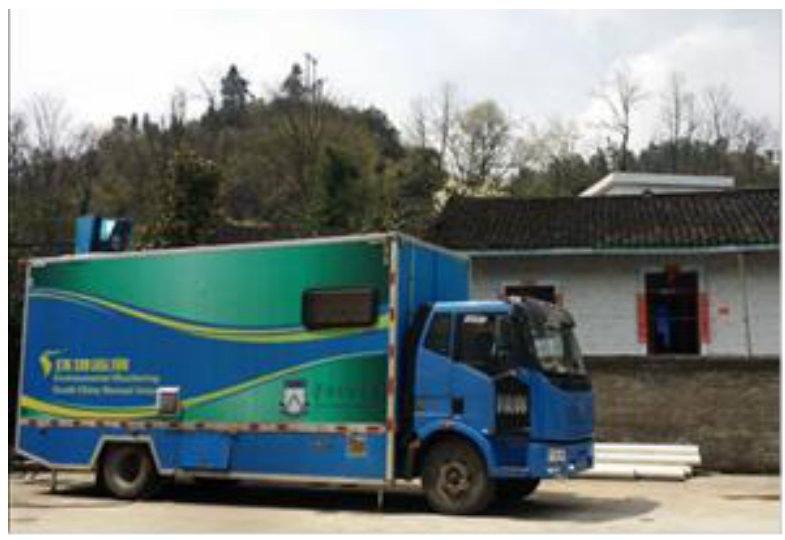

Fig. 1. The SCNU mobile differential absorption lidar system on site in the Wanshan mining area of China for atomic mercury monitoring. 
curve corresponds to a high concentration value. A detailed description of the mobile laboratory and its capabilities is given in [4].
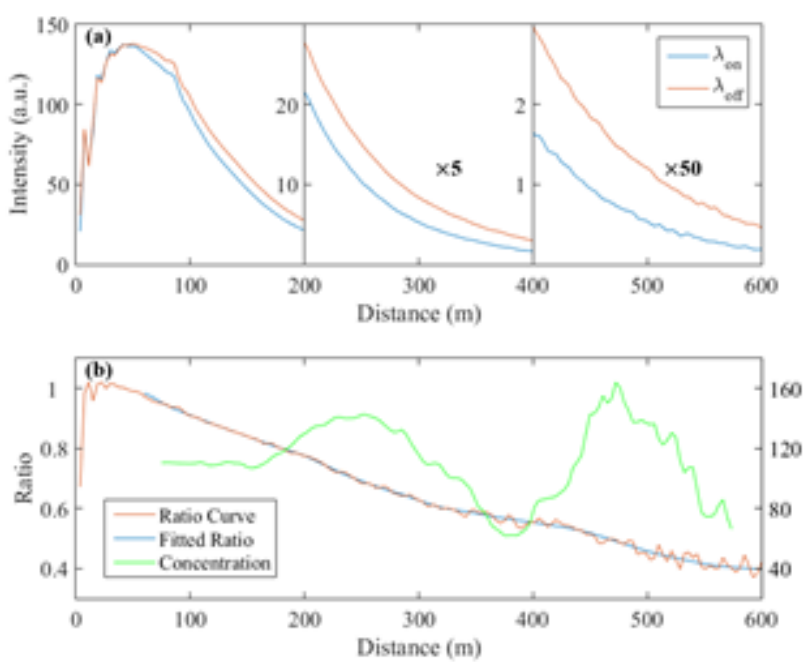

Fig. 2. a) Lidar recordings of atomic mercury for transmitted on- and off-resonance wavelengths. $b$ ) Divided DIAL curve, from which the rangeresolved concentration profile is derived [6].

We have used the mercury monitoring capability in a number of projects on the Chinese scene. These include monitoring in the major cities of Guangzhou [7], Zhengzhou [8] and Xi' an [9].

Particularly polluted areas are found in connection to the mining areas in the Guizhou province, in particular in the mercury mining areas in Wanshan [10,11]. Although official mining has been closed down in 2002, artisanal mercury extraction from the cinnabar ore in still ingoing, and there are large deposits of roasted ore, still containing high concentrations of metal mercury. We have pursued a mercury monitoring campaign together with the Chinese Academy of Sciences Institute for Geochemistry, Guiyang [6].

As mentioned, mercury is an interesting geophysical tracer gas [3]. Emission are related to geothermal energy, volcanic activity and ore deposits. In ancient China, it seems mercury, at the time considered as an elexir of life, was deposited in tombs of high officials as a gift of the emperor [12]. We have performed an exploratory atomic mercury investigation at the maosoleum of the "Terracotta Army" emperor Qin in Xi'an [13].

\section{RESULTS}

We found, that the mercury concentration in the air of the major cities in China, where we performed DIAL measurements was in the range $5-10 \mathrm{ng} / \mathrm{m}^{3}$, with occasionally higher values, especially during the very hot summer days in $\mathrm{Xi}^{\prime}$ an.

In the mining areas in Guizhou we observed very high concentrations of atomic mercury, in spite of the temperature during the campaign being modest, around 7-14 degrees. The recording in Fig. 2 from the Wanshan area reaches concentrations of $150 \mathrm{ng} / \mathrm{m}^{3}$. An overview of the measurement area in Wanshan is given in Fig. 3 . Examples of vertical scans in the three measurement directions indicated in Fig. 2 a) are shown in Fig. 4. The highest concentrations, observed in the Fig. 4a) are associated with air flow from the Longtangping mercury plant.
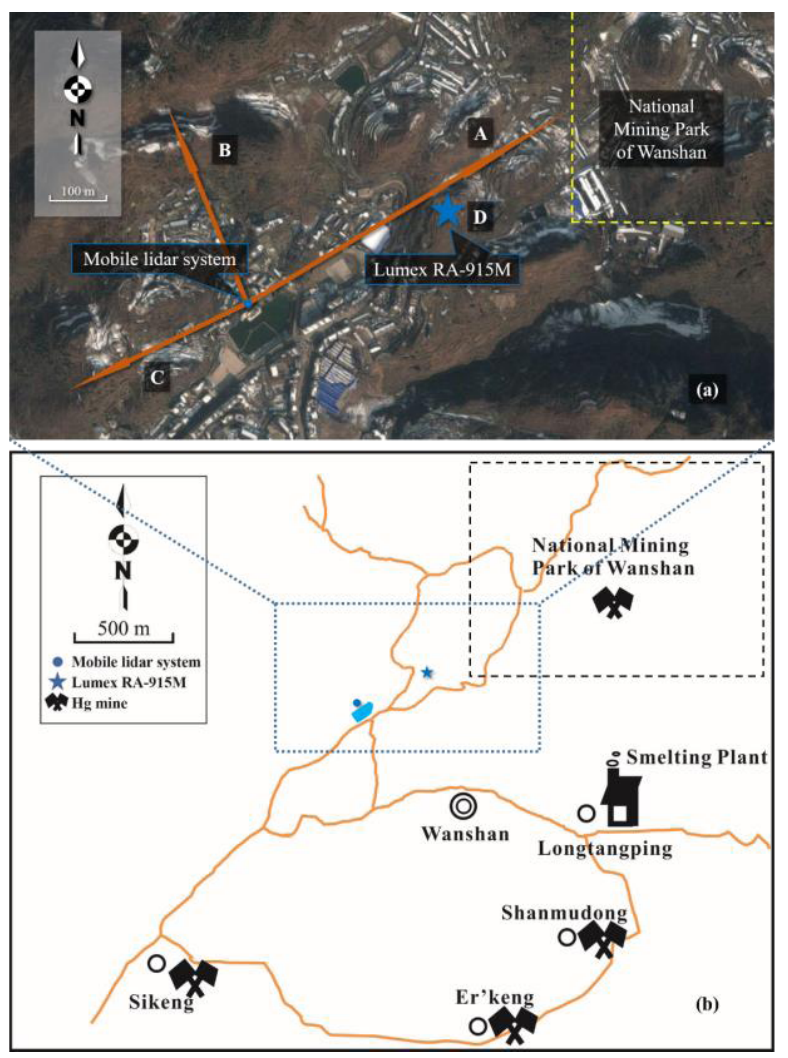

Fig. 3. Overview of the Wanshan area, with mining sites and the location of a cinnabar roasting plant indicated [6]. 


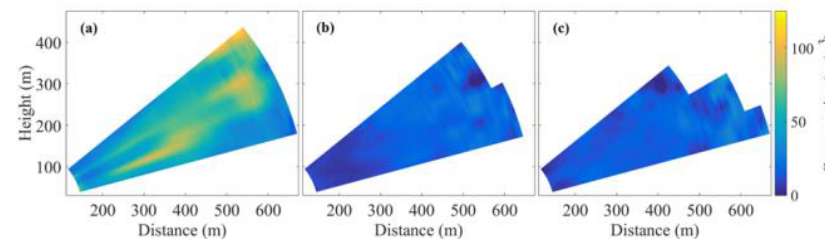

Fig. 4. a) Vertical scans recorded in the three directions indicated in Fig. 3a). Concentrations reaching $100 \mathrm{ng} / \mathrm{m}^{3}$ are observed in a direction intersecting the air flow from a mercury processing plant [6].

We performed an intercalibration between our lidar system and a Lumex Zeeman modulation mercury instrument [6]. The lidar data were found to be 9 percent higher than the Lumex data, possibly indicating that the DIAL cross section, for which no full consensus exists, should be correspondingly adjusted.

A photo from our measurements at the Emperor Qin mausoleum in Lintong, $30 \mathrm{~km}$ from the city of Xi'an is shown in Fig. 5. Three different locations were chosen for the lidar system, which performed scans over the slopes of the mound, with the laser beam positioned about 5 meters above the top of the vegetation, covering the mound. The results of our campaign are reported in Ref. [13].

\section{ACKNOWLEDGEMENTS}

The authors gratefully acknowledge the support of Prof. Sailing He. A fruitful cooperation with further colleagues as SCNU, and at Henan Agricultural University, Zhengzhou, and the Institute of Geochemistry, Chinese Academy of Sciences, Guiyang, is much appreciated. This work was financially supported by a Guangdong Province
Innovation Research Team Program under Grant No.201001D0104799318.

\section{REFERENCES}

[1] United Nations, Minamata convention on mercury. (2013)

[2] D. G. Streets, et al. Atmospheric Environment 39(40): 7789-7806 (2005)

[3] S. Svanberg, Optics and Lasers in Engineering 37, 245-266 (2002)

[4] G. Y. Zhao, et al. Applied Optics 56(5): 1506-1516 (2017)

[5] S. Svanberg, in Air Monitoring by Spectroscopic Techniques, (Eds: M. Sigrist), Wiley, N.Y. 1994, pp 85-161

[6] M. Lian, et al. Environmental Pollution 240: 353$358(2018)$

[7] G. Y. Zhao, et al. PIERS Guangzhou 2014, 27112714 (2014)

[8] M. Lian, G. Y. Zhao, Z. Duan, Y. Y. Li, S. Svanberg and J. D. Hu, Improvement of a Mobile Differential Absorption Lidar System and Measurements of Atmospheric Mercury in the City of Zhengzhou, accepted by Journal of Optoelectronics Lasers (2019)

[9] Z. Duan, G. Y. Zhao, S. M. Zhu, M. Lian, Y. Y. Li, W. X. Zhang, and S. Svanberg, Atmospheric mercury pollution in the $\mathrm{Xi}^{\prime}$ an area, China (to appear)

[10] Z. H. Dai, et al. Atmospheric Chemistry and Physics 12: 6207-6218 (2012)

[11] G. L. Qiu, et al. Journal of Agricultural and Food Chemistry 56(7): 2465-2468 (2008)

[12] H. Z. Liu, et al. Geophysical and Geochemical Exploration 37(4): 670-674 (2013)

[13] G. Y. Zhao, W. X. Zhang, Z. Duan, M. Lian, N. B. Hou, Y. Y. Li, S. M. Zhu, and S. Svanberg, Mercury Emission from the Emperor Qin Tomb in $\mathrm{Xi}^{\prime}$ an Studied by Differential Absorption Lidar, submitted (2019) 


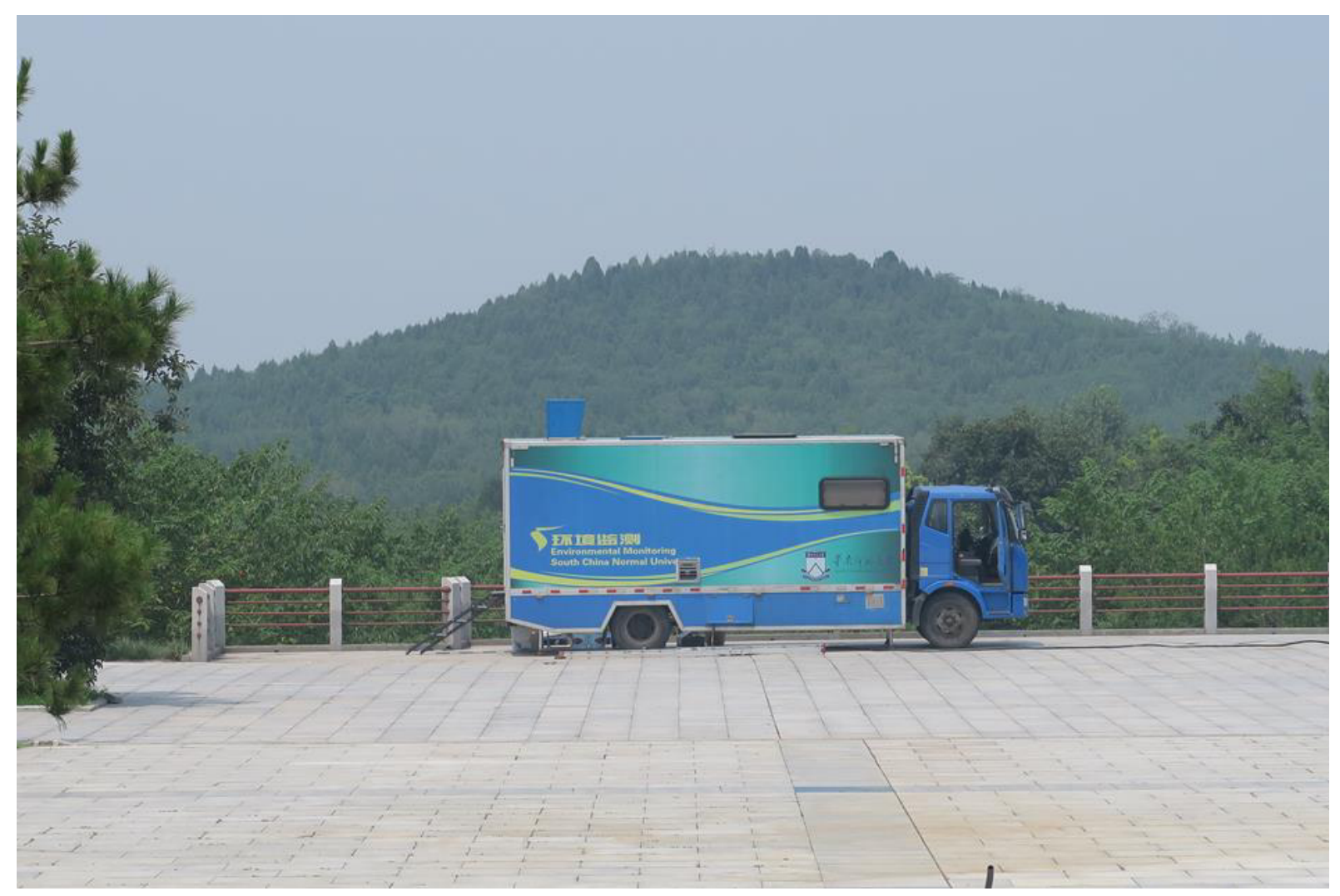

Fig. 5. Photograph from one of the lidar system measurement sites at the Emperor Qin Mausoleum area close to $X i^{\prime} a n$. 